\title{
Queering the Community Music Archive
}

\begin{abstract}
Archiving has become an increasingly important practice in the preservation of feminist and queer histories. In this article, we pay specific attention to the emerging body of literature on feminist archives of popular music, many of which are community-based, DIY initiatives. These community-led archives aim to comprehensively collect the ephemeral, intangible heritage of feminist music cultures that have traditionally been excluded in popular music canons and marginalised by mainstream heritage institutions. The literature revealed that feminist music archives function as much more than spaces for preservation - they are affective as much as they are intellectual, and they are key sites for activism and community-building.

These two themes - activism and affectivity - thread together the body of literature, providing both the driving force behind these DIY archives and their potentiality in the communities of interest they cater to. The community archivists accounted for in the literature have all engaged in practices of queering the community music archive; taking the mainstream heritage institution as a model and rebuilding it from the ground up, renegotiating its boundaries and notions of linear history, and reconfiguring its practices to account for lives lived in the margins of the mainstream.
\end{abstract}

\section{Keywords}

DIY archives, popular music, feminist histories, community archives, queer archiving

\section{Introduction}

This article provides an overview of feminist engagements with the Do-It-Yourself (DIY) archiving of musical forms related to gender, sexuality and feminism. It speaks to a growing interest in both the community archiving of popular music and the community archiving of LGBTIQ histories and cultures. Our aim is to provide a synthesis of the growing literature in the area of community-based, feminist and queer music archives in order to explore how the practices of queer and feminist music archives take on (both as 'adopting' and 'challenging') the model of mainstream archives and rebuild it from the ground up. With popular music archiving as a central frame, we structure the article using three organising themes identified from the literature: community archiving, feminist archiving and queer archiving. Given the overlap that exists between queer and feminist communities, and the technical requirements of archiving practices regardless of a collection's provenance, these themes are conceptual tools for organising data rather than actual divisions.

As scholars whose work is informed by feminist understandings of objectivity (Haraway 1988), and the implications of positionality in the production of knowledges (Rose 1997), we recognise the value in providing a positionality statement regarding those aspects of our lives and work that are likely to have influenced our research and analysis. All three authors of this paper are white Australians. The first and second authors are women, and the third author is a queer man. These aspects of our identities may inform how we approach our data collection and analysis. For example, our dominant racial identities mean that we may be inattentive to issues of race that do not directly affect us, or that benefit us to others' detriment or exclusion. We approach 
this article from diverse perspectives within the humanities and social sciences. We bring together our separate interests in popular music studies, cultural heritage, youth and urban studies, and queer and feminist studies. Our shared background in sociology provides us with grounding in reflexivity, through which reflection is ongoing regarding our processes of data collection (inclusion/exclusion of writings) and analysis (interpretation/s of writings), and the influence our various positionalities might have over these processes. Also underpinning this article, and specific to its focus, is expertise drawn from the Australian Research Council funded project: 'Do-it-yourself popular music archives: an international comparative study of volunteerrun institutions that preserve popular music's material culture' (in particular see Baker 2017). It is in the context of this project, and in the grassroots negotiations these institutions carry out with mainstream heritage institutions and practices, that the interest in the queering of community music archives has emerged.

To undertake our review for this article we sought published books, articles and reports using databases (Taylor \& Francis Online, International Bibliography of the Social Sciences, Expanded Academic ASAP and SpringerLink), and from bibliographies, reference lists and websites. The database search was conducted between 8 December 2015 and 19 January 2016. A supplementary search was conducted between 28 November 2016 and 8 December 2016 to capture subsequently published literature. Based on these searches, our review includes writings on community-led, DIY and grassroots archiving of feminist and queer histories, with a specific focus on archives of music cultures. The intention of the review was not to capture all available literature on queer and feminist archives but rather to draw on those pieces of scholarship that assist in contextualising the literature on community music archives. A breakdown of the focus of the literature reviewed in this article indicates that five dealt with both feminist and queer archives; 13 dealt with feminist archives (of which seven were focused on feminist music archives); and 23 dealt with queer archives. Additional sources dealt with DIY and community-based archives in a general sense.

What the literature revealed is that grassroots archiving of feminist and queer music histories involves inclusive and comprehensive collection mandates, which aim to preserve ephemeral and intangible cultural heritage. Further, these archives have significant affective and social functions, and aim to cater to the community of interest rather than a wider audience/academia. This is consistent with findings from the 'Do-it-yourselves popular music archives' project, which explored popular music heritage institutions that archive the material histories of other genres, such as jazz and country music (see Baker 2017). Yet the literature reviewed for this article also points to feminist music archives being distinct from DIY archives focusing on other forms of popular music culture because feminist music archives have explicitly activist aims as opposed to principally preservationist ones. This is not to suggest that other forms of community-based popular music archiving do not embody a form of activism, or that the enthusiasts who run those places are not activist archivists (see Collins \& Carter 2015). Indeed, the archiving of music genres which epitomise the DIY ethos, such as punk and riot grrrl, as well as zine archives which deal with an aspect of DIY music culture, are necessarily activist in their orientation due to the nature of the archive material (Freedman 2012; Dunn and Farnsworth 2012).[1] But the work 
on feminist music archives indicates that, akin to other community archives documenting minority or marginal communities (see Flinn 2007; Flinn, Stevens \& Shepherd 2009), these are places of heritage propelled by an overtly 'political agenda in which preservation and use of historical materials might play a role in serving a set of political aims (be they educational, commemorative, empowering, or transformative)' (Flinn 2011, 8). Given this distinction, the archiving of feminist and queer histories, and the literature about these practices, has great potential to inform scholarship on popular music archiving more generally, including in other DIY institutions focused on preserving the popular music heritage of diverse communities of interest.

It is also worth reflecting on the point at which DIY practices of archiving may become institutions; that there is, for example in Roberts and Cohen's (2014) typology of popular music heritage, a variant of heritage practice that does not necessarily see itself as heritage practice, and might be constituted by personal collection or dissemination of materials (Baker 2015a). The work of Baker and Collins (2016) also highlights that the archiving of popular culture should be understood as a continuum of practice in which there is movement between the grassroots beginnings of an archive and, over time, the possibility of securing a level of legitimation or authorisation such that it emerges as a mainstream heritage institution. That is, none of the archives discussed in this article are fixed in place but rather move back and forth along a continuum based on access to resources (time, space, money, people) which ultimately determine the lifecycle of an archive (Flinn 2011).

\section{Community Music Archives}

Recently in the field of popular music studies there has been an increasing interest in issues of heritage, particularly the collection, curation and preservation of popular music's material past. This is evidenced in the 2015 publications of the edited collections Sites of Popular Music Heritage (Cohen et al 2015) and Preserving Popular Music Heritage (Baker 2015a). The latter book has as its sole focus community-led heritage initiatives, particularly archives and museums, and, in particular, what Baker and Huber (2013) call 'DIY (do-it-yourself) institutions'. DIY institutions are a subset of community archives, described by Flinn as 'grassroots activities of documenting, recording and exploring community heritage in which community participation, control and ownership of the project is essential' (2007, 153). For Baker and Huber (2013), DIY institutions encompass those popular music archives, museums and halls of fame that are founded by enthusiasts, are run largely by volunteers, and which exist outside the frame of national or mainstream institutions of collecting and display. The focus of Baker and Huber's research is on heritage activity being conducted largely without the aid of experts trained in the archival/museal professions. These institutions are also characterised as being in a continual struggle for their long-term futures, with issues of sustainability linked to financial, spatial, human resource, and technological constraints, and, increasingly for digital sites of communityled popular music heritage, also copyright and legal challenges (see Baker \& Collins 2015, 2016).

Baker (2017) argues that DIY institutions are significant epistemologically because the parameters of their heritage activities, practices and processes are determined by volunteers and enthusiasts embedded in the cultures being preserved. This enables different kinds of 
archival records or museal displays to be created than those that are governed by the policies and fiscal constraints of national institutions. While DIY institutions principally have a cultural function, in that they are founded specifically to preserve (in)tangible cultural heritage, Baker and Huber (2013) also identified social and affective dimensions which render them distinct from mainstream archives and museums. As Baker $(2015 b, 59)$ has gone on to assert, DIY institutions 'are concerned with cultural heritage management and the preservation of artefacts, but they are also extensions of musical communities in the present in which activities around music preservation have personal, community and heritage benefits'. As such, these are affective institutions, borne from the affective investments of their founders, and which foster emotional connections between volunteers and the objects they care for. The result, Baker argues, is 'a different kind of archival and/or museal space, one in which affect is fostered and, indeed, privileged' (2015b, 48). This emphasis on affect can also be found in work exploring queer and feminist archives (see, for example, Cvetkovich 2003).

The DIY institutions discussed in Baker's research are part of a broader movement in community-based ownership over archival and historical material which has been identified by Flinn (2007). The recent archival turn in popular music studies can also be observed in feminist and queer scholarship (Reitsamer 2015; Cooper 2015; Eichhorn 2010, 2013) and an increased focus on queer and feminist archiving is also evident in the field of information studies (Keilty \& Dean 2013). The interest of this article begins at the point where these grassroots initiatives/institutions with a focus on affective communal/community histories converge. Reitsamer $(2015,91)$ notes in her contribution to Preserving Popular Music Heritage that 'Feminist archives dedicated to the production and preservation of women's, feminist and queer music-making ... have hardly been explored'. We consider here the work of Withers (2014, 2015a, 2015b) and Eichhorn (2010, 2013) whose scholarship addresses this gap and which adds to our understanding of the DIY institution through its concern with a political activist agenda that goes beyond DIY as an everyday intervention in the preservation of and ownership over the material histories of popular music culture. To understand the work of Withers and Eichhorn, and others looking at queer and/or feminist popular music archives, we need first to explore the broader literature on queer and feminist archiving as this provides context for understanding the practices of community archiving of popular music culture, and specifically of feminist music cultures, investigated by those scholars.

\section{Queer and Feminist Archives}

As the scholarly interest in DIY and community-based archiving grows - of which music archiving and heritage is a subset - so has a body of literature emerged focusing specifically on queer and feminist archives. Our review of this literature is not exhaustive, but includes several books (see Kumbier 2014; Halberstam 2005; Cvetkovich 2003), edited collections (see Keilty \& Dean 2013; Bly \& Wooten 2012), journal articles (see Caswell \& Cifor 2016; Chenier 2016; Cooper 2015; Taavetti 2015; Samer 2014; Sheffield 2014, 2016; McLeod et al 2014; Eichhorn 2014; Manalansan 2014; Madden 2013; Wakimoto et al 2013; Boulay et al 2012; Darms 2012), and special issues by journals such as Radical History Review ('Queering Archives: Historical Unravelings', 2015) and Archivaria ('Special Section on Queer Archives', 2009). 
Marginalised groups, such as women and queer communities (gay, lesbian and bisexual; trans* and intersex; and various other sub/cultural groupings of sexual/gender dissidents), have traditionally been excluded altogether or had their minoritarian status erased from mainstream historical narratives and heritage institutions (Cooper 2015; Taavetti 2015; Wakimoto et al 2013; $X$ et al 2009; Cvetkovich 2003). As a consequence, they have been responsible for establishing their own collections, archives and museums to preserve their histories, to save what is at risk of being lost. Initially, these archives were mostly DIY, grassroots, community-based efforts initiated by activists with little funding, limited space and often no professional archival skills (Kumbier 2014; Eichhorn 2010; Cvetkovich 2003). These types of archives still exist today, but there are also increasingly more queer and feminist collections held in established and 'mainstream' institutions such as universities (some of which were started by donations from now-defunct grassroots archives [Eichhorn 2010, 2013]).

The strengths and weaknesses of both community-based, DIY archives and mainstream, institutional archives are frequently debated in the literature. The functions, practices and motives of community-based archives may be seen as more closely aligned with the values and ideologies of queer communities and feminists and their methods of cultural production. That is, there is a common desire for autonomy, independence and self-determination - to do it themselves, on their own terms (Cooper 2015; Withers 2014, 2015a; Kumbier 2014; Freedman 2012; DiVeglia 2012). There is widespread distrust towards capitalist, patriarchal institutions (whether that be the publishing industry, music industry, or the academy) because of how these establishments have so rigorously excluded, oppressed and marginalised them (Mitchell 2015; Cooper 2015; Withers 2014; Kumbier 2014; Wakimoto et al 2013; DiVeglia 2012; Eichhorn 2010; Cvetkovich 2003; Thistlethwaite 1998; Nestle 1990). Thus, there is a common desire to operate outside of these institutional constraints.

In opposition to these 'elitist' (Thistlethwaite 1998, 155) institutions and the historical canons they produce, the collection practices of community-based archives tend to be comprehensive rather than selective, and are just as interested in the everyday as the extraordinary (Sheffield 2014). For example, the Lesbian Herstory Archives (LHA) has a specific mandate to collect 'all things lesbian' (Thistlethwaite 1998, 155). One of the LHA's founders, Joan Nestle, notes that the archivists have long been trying to stress to women that 'all lesbians [are] worthy of inclusion in herstory' $(1990,87)$, not only the pioneering or well-known lesbians. Not surprisingly, the archive is aimed at catering to these 'everyday lesbians' whose histories they preserve, rather than academics (as is usually the case with institutional archives). This desire to provide a comprehensive historical record is also evident in the DIY popular music archives of Baker's research, discussed above.

Community-based archives may also be seen as more accessible since they are not only limited to use by researchers (DiVeglia 2012). This is particularly true of digital archives, which have the potential to reach large audiences and increase the visibility of relatively unknown groups and movements (Chenier 2016; Withers 2014; DiVeglia 2012). As DeVeglia (2012, 80) observes, many donors are motivated not only by a desire to make their collections available to historians and researchers, but to make them available as a resource to the wider queer 
community, 'especially to new or isolated community members for whom they act as an important anchor and source of identification'. In spite of this, as Eichhorn $(2010,2013)$ explores in her work, some donors prefer their collections to be held by established institutions for a number of reasons (as will be outlined below).

Rather than positioning community-based archives and mainstream institutions as in competition with one another, it is more productive to think in terms of how they might work in parallel, or even in partnership (Chenier 2015; Baker 2015b; Eichhorn 2013, 2014). Brager and Sailor (2012) suggest that the two models can learn from each other: community-based archives can emulate the practices of professional archivists, and mainstream institutions can adopt some of the approaches of grassroots initiatives by aiming to be more inclusive of and sensitive to the communities they archive. DiVeglia (2012) argues that it is imperative for professional archivists to be accountable to the communities they archive, respect their privacy, involve them at every possible stage, and strive for greater accessibility. Contrary to the outdated ideal of an objective archivist, an archivist sensitive to the concerns of such communities should promote these communities' causes and act as advocates for them, not just collect and preserve their histories (DiVeglia 2012). As Caswell and Cifor $(2016,23)$ point out, archivists should demonstrate 'radical empathy' towards all parties involved in the creation and existence of the archive, including donors, creators, subjects, visitors and the wider community. That is, archivists should be attentive to their affective and ethical (not only legal) responsibilities (Caswell and Cifor 2016).

The contents of queer and feminist archives are frequently mass-produced, everyday, ephemeral materials (Kumbier 2014; Sheffield 2014, 2016; Wakimoto et al 2013; Cvetkovich 2003). Cvetkovich $(2003,243)$ suggests that this is due to the queer community's 'concern with sexuality and leisure culture as well as with legacies of grassroots political activism'. We would add that the importance of these mass-produced, everyday, ephemeral materials to these particular communities also relates to their embeddedness in the dominant: what is given to them to work with as community- and identity-building materials are the products of a dominant culture. Queer and feminist cultural production has traditionally used DIY methods to produce large quantities of ephemera (Eichhorn 2013), often by re-making, re-using or re-tasking the ready-made products of the dominant (patriarchal, heteronormative) culture. These archives collect anything ranging from zines, posters, VHS tapes and DVDs, to oral testimonies, personal photographs, letters, journals, and transcribed or filmed interviews, to born-digital content like emails, Facebook groups or blogs (Cooper 2015; Kumbier 2014; O'Meara 2012; Cvetkovich 2003).

Traditionally, these kinds of ephemera have not been deemed as important or valuable by conventional heritage standards (Sheffield 2016; Kumbier 2014; Wakimoto et al 2013). While their 'historical value' may be contested, they are nonetheless worth collecting and preserving for their 'felt value' (Brager and Sailor 2012, 47). As Cvetkovich (2003, 243-244) argues: 'In insisting on the value of apparently marginal or ephemeral materials, the collectors of gay and lesbian archives propose that affects-associated with nostalgia, personal memory, fantasy, and trauma-make a document significant'. She contends that there needs to be alternative, 
unorthodox approaches to archiving and documentation to cater to the deeply affective and ephemeral nature of the materials and stories produced by queer people. We note, of course, that the significance of ephemera is not confined to queer and feminist archives and to the communities they serve - indeed, DIY music archives are often based on the collection of ephemera generated by a music industry geared towards the production of 'stuff' that goes well beyond the intangible music commodity (Leonard 2007). Traces of the past held in ephemera are frequently all that survive from marginal histories. Therefore, ephemera is often central to community-based archiving, especially within those communities whose members' lives are marginalised.

Since queer archives frequently document traumatic events, oppressive regimes and private struggles, they are what Cvetkovich (2003) conceptualises as 'archive[s] of feelings'. They are repositories of trauma, shame and mourning, but also love, celebration and pride (Taavetti 2015; DiVeglia 2012; $X$ et al 2009; Cvetkovich 2003). How people engage with the archive is an affective experience as well - archives can trigger the resurfacing of painful memories, but can also elicit feelings of pleasure, excitement, catharsis, inspiration or empowerment (Petro 2015; Cooper 2013; Piepmeier 2012; Eichhorn 2010; Cvetkovich 2003). For instance, in examining the digital queer archive BishopArchive.org, which documents experiences of sexual abuse in the Catholic Church, Petro (2015) notes that retelling, sharing and reading these personal histories can be difficult for survivors. At the same time, bringing attention to painful individual pasts serves to allow for the mourning and remembering of its victims, to hold accountable those institutions who were responsible for their suffering, and to contribute to a sense of collective memory (Taavetti 2015; DiVeglia 2012).

For queer communities, the archive can be a 'safe space' in which to explore these feelings and histories (Cooper 2015; Wakimoto et al 2013; Cvetkovich 2003). The Lesbian Herstory Archives, for example, intends to have a 'home-like atmosphere' (Cooper 2013, 531) to foster a sense of comfort and trust among its visitors. This is especially important for new members of the queer community as they can have a space to learn about themselves and their heritage and create networks with other queer people (Wakimoto et al 2013; DiVeglia 2012). Thus, these archives function as social institutions (Baker \& Huber 2013) in that they can provide a space for meeting and collaboration based on shared interests and identities, connecting diverse groups such as scholars, archivists and community members (Moore 2017; Chenier 2016; Wooten 2012; Eichhorn 2010). These connections promote education and can propel activism (Eichhorn 2013).

Such archives are, however, vulnerable and much like other DIY archives, the long-term sustainability of community-based queer and feminist archives is a central issue. As mentioned above, the potential longevity of an archive can be a significant factor in how donors determine where to house their collections. In this sense, community-based archives may appear more fragile as they face challenges with maintaining financial, spatial and human resources (Baker \& Collins 2015). That is, common issues include the availability of ongoing funding from tenuous sources like membership fees, grants and donations; threats to archival space from possible evictions, fires or floods; and the succession planning necessary to ensure custodianship of the 
archive is taken over as the founder(s) and volunteer workforce age, fall ill or die (Baker \& Collins 2015; Cooper 2015). The latter point is particularly important considering many of these archivists may be resistant to their collections ending up in established institutions if their DIY endeavours were to collapse. The Lesbian Herstory Archives is one example of an archive that has been adept in handling these issues, with a mandate to pass on archival practices to the younger generations of lesbians who frequent it (McKinney 2015; Samer 2014; Eichhorn 2013). The success of this has been attributed, in part, to the Lesbian Herstory Archives' commitment to adapting to changing understandings of gender, sexuality and feminism, such as through becoming more inclusive of transgender people (Samer 2014; Eichhorn 2013).

Archives do not only serve to inspire activism, however - archiving is a form of activism in itself (Kumbier 2014; Piepmeier 2012; Gumbs 2012). Reclaiming history through the archive is a political act in that it has the potential to make the invisible visible, restore voices to marginalised groups, legitimise them as worthy of preservation, challenge mainstream historical canons, and reshape cultural memory (Taavetti 2015; Petro 2015; Withers 2014; Wakimoto et al 2013; DiVeglia 2012; $X$ et al 2009). The archive, then, is never only preoccupied with the past, but simultaneously oriented towards the present and future. It is never merely documenting and preserving, but actively and affectively identity- and community-building into the hereafter. The literature on queer archives highlights the importance of community-led, DIY heritage institutions for preserving the histories of marginalised groups and contributing to the ongoing activism of these communities.

\section{Feminist Music Archives}

While there is evidently a growing body of literature on feminist and queer archives, as identified earlier by Reitsamer (2015) only a handful of these consider archives of popular music cultures, and those that do tend to concentrate on feminist or gendered archives. Work on archives of queer popular music is largely peripheral. Eichhorn's $(2010,2013)$ work deals with feminist collections associated with zines and Riot Grrr; Withers (2014, 2015a, 2015b) focuses on music-making during the UK Women's Liberation Movement, and its digital archive which she co-founded; Mitchell (2015) examines Fem FM, the UK's first women's community radio, and the archive which she helped establish to document it; and Reitsamer (2015) draws on a range of examples of DIY feminist archives, both physical and digital. Common among the feminist music cultures explored in these works are independent, DIY forms of cultural production, whether through making music (Withers 2015b), radio (Mitchell 2015) or zines (Eichhorn 2013).

In The Archival Turn: Outrage in Order (2013), Eichhorn traces how Riot Grrrl zines gained traction in North America following the decline of the feminist publishing industry during the 1990s. This industry had thrived during the 1960s to 1980s as second-wave feminists established their own presses, bookstores and publishing networks in resistance to the capitalist, patriarchal mainstream publishing industry (Eichhorn 2010). In the 1990s, however, no longer able to publish through the same avenues, women began creating (cutting, pasting, photocopying), disseminating and collecting zines as a part of the Riot Grrrl movement. Much like their predecessors, the self-publishing women of third-wave feminism were interested in producing documents that could be made 'quickly, inexpensively, and, most notable, without 
vetting from outside publishers or potential censorship imposed by commercial printers' (Eichhorn 2013, 71). Due in part to their ephemeral nature, zines were seen to lack the prestige and 'symbolic currency' of the previous generation's forms of cultural production and their value was initially not widely acknowledged by older feminists (Eichhorn 2010, 639).

Music-making during UK Women's Liberation Movement, as explored in Withers' (2014, 2015a, 2015b) work, shared a similar ethos and approach. The women involved were strongly opposed to the capitalist, sexist nature of the music industry, and favoured independent methods of music-making over the potential exposure offered by the 'malestream' (Withers 2014, 691). With limited resources and funds, the women produced few 'finished' recordings, let alone professionally-recorded tracks, and garnered little exposure beyond an audience of feminists who were already directly involved in the movement in specific places and times (Withers 2014, 2015b). Thus, it lacked the kind of concrete, recorded legacy typically required to be included in music canons (Reitsamer 2015; Withers 2014, 2015a).

The DIY, ephemeral, anti-commercial practices and products described above are not what is conventionally considered worthy of historical preservation. Withers (2015a, 2015b) argues that these ephemeral practices are indeed legitimate and important, and can be deemed 'intangible cultural heritage'. Central to this kind of heritage are performative practices, expressions and traditions (for example, storytelling, dance or music-making) which are passed down (transmitted) to future generations (Withers 2015a, 2015b). Intangible cultural heritage is always flexible as traditions are continually re-enacted, re-shaped and transformed through practice (Withers 2015a). Archives (particularly community-based archives) have become central tools in the preservation and transmission of intangible cultural heritage (Withers 2015a, 2015b).

In her work, Eichhorn $(2010,2013)$ asserts that archival spaces and practices are central to feminist cultural production, activism and knowledge-making. Drawing on Foucault's genealogy, she suggests that examining the past can allow us to critically analyse and deconstruct present conditions. A genealogical approach works to defamiliarise what is assumed to be stable or natural in contemporary life, such as particular social structures and conventions, by revealing that they are not historically normative nor static (Eichhorn 2013). Genealogy has the potential to transform the present through a consideration of the past, queering linear conceptions of temporality (Eichhorn 2013). Eichhorn $(2013,30)$ posits that this queerness is characteristic of the feminist collections she explores in her book - they have the 'remarkable ability to be in time differently - to recognize the past as a way to reinvigorate a beleaguered present and to recognize the future as always already implicated by the pull of the past'.

The potential for archives to have present political effects is at the heart of the 'archival turn', which marks an increase in archival practices among women born during and after secondwave feminism (Eichhorn 2010, 2013). This coincided with the 'neoliberal turn', under which anti-economic initiatives like the feminist publishing movement collapsed and women had to find new ways to legitimise their knowledges - namely, through the archive (Eichhorn 2013). As an 'authorizing apparatus' (Eichhorn 2013, 15), the archive had the ability to assign historical significance to feminist legacies, knowledges and forms of cultural production (Eichhorn 2010, 
2013). By bringing the lives and voices of feminists back into the public sphere, archiving restored a sense of political agency that was eroded under neoliberalism (Eichhorn 2010, 2013). Thus, archives are at once devoted to preserving the past and developing feminism in the present and for the future - they are not simply repositories of recovered histories, but also sites for the production of feminist knowledges and activism (Eichhorn 2010, 2013).

The archival turn is at odds with assumptions underpinning generational debates in feminist scholarship. Eichhorn (2013) observes that the supposed conflict between second-wave and third-wave feminists is often expressed in terms of 'loss narratives' and 'progress narratives' older generations feeling that feminism's purpose has been lost, and younger generations disregarding second-wave feminism as outdated, misguided or problematic. Third-wave feminists were portrayed in the literature as ungrateful to their predecessors, disinterested in feminist histories and focused only on fleeting engagements in the present (Eichhorn 2010, 2013). These debates obscure the ways in which contemporary feminists are interested and invested in the past and the future, as demonstrated by the archival turn (Eichhorn 2013).

Out of an 'archival impulse', third-wave feminists have been collecting not only their own generation's cultural products (such as zines), but also documents from past movements (Eichhorn 2013). This is motivated as much by affective factors as intellectual ones, and demonstrates an appreciation for the feminists that have come before them (Eichhorn 2010, 2013). Eichhorn (2013) explores these relations through a consideration of how the younger generation engages with feminism's 'scrap heap' - the marginalised stories, forgotten documents or 'failed' movements. For instance, after the first feminist archives (created in the 1930s and 1940s) collapsed, their scrap heap was dispersed across the world and laid the foundations for both community-based and institutional archives to be established decades later (Eichhorn 2013).

As Eichhorn (2013) puts it, documents and subjects have 'afterlives' - they can be important not only for what they achieve (or fail to achieve) at their time of creation, but for how they may be mobilised as a resource for thinking and action later on (Reitsamer 2015; Withers 2015a). That is, despite what generational metanarratives might imply, the ideas, values, practices and goals of feminists at any given time are varied and can traverse multiple eras (Withers 2015b). Archives, as accumulations of bits from the scrap heap, are spaces which draw together artefacts from different times, elucidate continuities with the past and foster dialogue and alliances between generations of feminists (Mitchell 2015; Reitsamer 2015; Eichhorn 2013). In this way, the archive has the power to undo generational logics and promote new, fluid narratives of feminism (Reitsamer 2015; Eichhorn 2013).

While it is widely understood that modes of historical preservation such as archives work to transmit particular values and knowledges, the technical processes of this transmission are often overlooked (Withers 2015b). That is, the type, form and style of the archive - physical or digital, institutional or community-based (see Baker and Collins 2015) - shape the ways in which heritage is constructed, curated, communicated and engaged with. In Feminism, Digital Culture and the Politics of Transmission: Theory, Practice and Cultural Heritage (2015b), 
Withers considers how the transmission of feminist histories (what she calls 'feminism's alreadythere') operates in a digital context, drawing on her experiences as co-founder of the online, community-based Women's Liberation Music Archive (WLMA).

Withers (2015b) explains that she was compelled to start the archive out of a feeling of frustration with the inaccessibility and inactivity of Women's Liberation Music (WLM) artefacts in physical archives. Using freely available digital tools like Wordpress, SoundCloud and YouTube, Withers was able to start her own archive with co-founder Frankie Green, a musician from the WLM era. The founders of the WLMA used a collaborative, community-led approach by consulting with other archivists and musicians, and by incorporating the testimonials of women who were involved with the WLM (Reitsamer 2015; Withers 2015b). Choosing a digital medium was especially appropriate for a repository of this kind - both the content and form of the archive are processual in that the artefacts are incomplete, rough works-in-process, and the blog is dynamic and characterised by a temporal 'liveness' (Withers 2015b, 152). This is what Withers $(2015 b, 150)$ calls an 'archive of process'.

The digital sphere offers the possibility to increase visibility of marginalised groups and cultures which have lingered 'on the fringe of cultural memory' (Withers 2014, 695). A digital archive can be created by an enthusiast with little to no archival training or funding, and with a significantly larger potential audience than a physical archive (Withers 2014, 2015b). Further, and of particular importance to feminists, the grassroots digital archive allows for self-determination and independence from institutional constraints. There are, however, limitations to digital archives, especially for amateurs. While digitisation is often assumed to extend the life of analogue materials, they may in fact be just as ephemeral. For example, Withers $(2015 b, 137)$ recalls errors she made as an amateur archivist, such as making low-resolution scans of photographs and digitising audio into low quality MP3 files. Although these digital versions were 'flimsy' by preservationist standards, they were 'ideal ... for internet distribution', which was her primary concern at the time. This reflects the tendency for feminist activists to privilege 'accessibility over durability' in their forms of cultural production and in archival practices (Eichhorn 2013, 71). Of course, even when the highest possible quality of digitisation processes are used, rapid advances in technology mean tools and file formats can still eventually become obsolete.

Preservation is not the only concern for community-based archives like the WLMA - by placing the archive in the digital realm, the archivists are re-circulating and transmitting feminism's past so that it can be used (Mitchell 2015; Withers 2014). They are making traditions, practices and knowledges available to be re-interpreted, re-enacted and transformed in the present and into the future. As Withers (2015b) contends, this access and engagement is essential for the continuation of feminist thought and activism.

In some cases, however, accessibility of collections is not the primary goal. Drawing on the example of The Riot Grrrl Collection at New York University's Fales Library and Special Collections, Eichhorn (2013) offers several reasons as to why donors, even those from antiinstitutional, DIY movements like Riot Grrl, might choose to donate to a physical, established 
archive which limits access to researchers and the community. Donors like Kathleen Hanna remarked that they felt an established institution had a greater chance of longevity due to more consistent funding and more adept preservation techniques by professionally trained archival staff (Eichhorn 2013).[2] Additionally, by contextualising the Riot Grrrl zines among a large collection of other artistic and cultural artefacts, the archive can authorise them as significant within a broader feminist history and legitimise the zines as cultural (rather than merely subcultural) products (Eichhorn 2010, 2013). Despite their differences, Eichhorn $(2013,43)$ observes that the archivists in these established institutions still wish to emulate some of the practices and mandates of their community-based counterparts, particularly in terms of how they balance 'preservation, education, and action'.

Reitsamer (2015) expands on the work of Eichhorn and Withers, arguing that DIY feminist archives challenge male-dominated popular music canons by documenting alternative histories and counter-memories. The European feminist music archives of her study - Archiv Frau and Musik (Women and Music Archive), Her Noise Archive, Dig Me Out, the WLMA, and the Jenny Woolworth Women in Punk Archive - vary in form, workforce and methods, but they also share certain commonalities (Reitsamer 2015). As DIY archives, they strive to be inclusive and comprehensive in their collection mandates, and they share a participatory, do-it-together approach to archiving (Reitsamer 2015). Since they aim to be resources to support feminist activism, there is also a shared emphasis on accessibility and outreach (Reitsamer 2015). Mitchell (2015) reflects on similar approaches in her case study of the Fem FM community radio archive - materials were digitised and placed online to improve access, raise awareness of the radio station's history, and to encourage participation and collaboration among interested women. As each of the examples above highlight, feminist music archives are simultaneously concerned with preservation, nostalgia, education, scholarship, community-building, and promoting activism. At the same time, these archives constitute a type of activism in themselves, queering conventional notions of heritage, temporality and collective identity.

\section{Conclusion: Queering the Community Music Archive}

This article draws on an emerging body of work on queer and feminist DIY community-based archives, with a view to music cultures. As noted in our introduction, the literature revealed that the grassroots archiving of such histories involves a set of practices that is often more inclusive and comprehensive in their collection of community products that mainstream institutions, aiming to preserve cultural heritage that is often ephemeral and intangible, yet is seen as valuable for community- and identity-building purposes.

Processes for undertaking this kind of preservation may draw from traditional and professional archival/museal practice, but often has approached the material to be preserved with a view to an immediate availability for use that may not align with best practice for long-term preservation (due to lack of knowledge, or lack of resources). For example, Withers' (2015b) early 'errors' in scans of photographs and digitised audio still produced ideal formats (low-resolution images and MP3s) for digital storage and presentation and, hence, for online accessibility. One result, across the DIY institutions examined in the literature, has been ad-hoc and creative employment 
of diverse approaches to preservation (including the use of a range of freely available online tools and resources) and non-traditional venues, as in online-only archives like the WLMA.

The value in the literature on archiving feminist and queer music histories, and more broadly, on archiving feminist and queer cultural histories, is in the potential to inform queer and feminist scholars, activists and archivists attending to community-based archives. The possibility of the DIY institutions of other diverse communities of interest who are focused on preserving their own (popular music) heritage, learning from what has come before - but has not, until relatively recently, been thoroughly documented - provides another opportunity arising from this valuable body of research. There is, of course, the possibility of mainstream institutions adopting some of the practices (and, perhaps, the activist/affective purposes) of these DIY, community-led institutions. This cross-pollination of DIY ideas and ideals is potentially the most valuable product of the body of literature reviewed for this article. Given the inherently political nature of feminist and queer archives (whether of popular music, or of culture more broadly), we identify four key recognitions emerging from the literature about these heritage institutions:

First, a recognition of the unavoidably political nature of archives (mainstream and DIY, community-based), regardless of any structuring ideology of 'objectivity' (and embracing this as a means to provide a ground for including diverse, minority, and alternative voices/stories in mainstream cultural canon). Second, a recognition of alternative ways in which culture is produced, and the contribution of DIY institutions for preserving these (ephemeral, intangible) products both respectfully - with a view to their communities of interest - and 'properly' - as mainstream heritage institutions are best known for. These other forms of knowledge, developed from the ground up, at the grassroots, are invaluable resources and the shift to participatory models of archiving where mainstream and DIY archival practice can be mutually informing are central to this (Huvila 2008; Gilliland and McKemmish 2014). Third, a recognition of the presence and value of 'affect' in what may seem like mere everyday objects, but are also the identity-building materials of marginal peoples who must work with the mass-produced commodities of the dominant (capitalist, consumer) culture in which they are situated. And fourth, a recognition of the value of making the preserved products available for use, by members of their home community (for further identity- and community-building), and by others (for education).

Much of the research on feminist community music archiving has focused on the activist and affective drives to preserve these histories, and also on the activist and affective potentialities produced by such practices. In this way, scholarship in this area is focussed on both the past how best to account for hidden histories and to present these histories as real, lived, felt - and the future - how best to bring such histories to bear on the world to elicit change and to provide archival content as affective; as identity- and community-building material. This simultaneous orientation to past and future, to activism and affect, is a thread shared between those DIY institutions depicted in the literature, despite their diverse aims and their servicing of very different groups of people. Indeed, affect and activism are increasingly recognised as central to archival practices. See, for example, the recent special issues of Archival Science (eds Gilliland and Cifor 2016; eds Flinn and Alexander 2015). 
In their approaches to the preservation of the music and, inevitably, the cultural histories of women and LGBTIQ communities, the archivists involved have necessarily queered traditional notions and practices of archiving. They have dealt with histories and herstories that are nonlinear, disconnected, and contradictory. The progressive waves of feminism and the letters of that comprehensive acronym 'LGBTIQ', do not always sit comfortably alongside one another. Likewise, in the scholarly analysis of these archives and their practices, there is a need to evaluate their approaches with an eye to the communities whose music histories are being preserved rather than to 'proper' or canonical understandings both of archiving and history.

There is value in queering the community music archive, based on our analysis. Quite apart from any vertical influence that may derive from queer and feminist archives upward, to the mainstream institutional archive - which may indeed serve as a generative line of further research - there is significant potential in the horizontal proliferation of practices and knowledge among other community archives. An understanding of queer and feminist archiving might inform other approaches to community archiving in a number of ways. All community archiving must, for instance, confront the problem of sustainability in some way (whether it manifests in the form of funding shortages, space and storage issues, the attenuation of volunteer workforces over time, and so on). Queer and feminist community archives are finding it necessary to develop ways to address this issue that may prove useful to similar organisations. And, vice versa, queer and feminist community-based archives can learn from their contemporaries in other areas. Sharing what works and what does not with other communitybased archives produces an interdisciplinary and cross-cultural body of knowledge that can more closely address the challenges diverse organisations in the heritage sector are likely to face. This is a more pragmatic approach to dealing with the issues community archives may confront than would be borrowing from the playbook of mainstream archives, which is populated by a set of problems and solutions that are qualitatively different, and which addresses itself to the history of an invented subject (the Everyman) who is all too singular.

\section{References}

Baker, Sarah, ed. 2015a. Preserving Popular Music Heritage: Do-it-Yourself, Do-it-Together. Routledge: New York.

Baker, Sarah. 2015b. "Affective Archiving and Collective Collecting in Do-it-Yourself Popular Music Archives and Museums" In Preserving Popular Music Heritage: Do-it-Yourself, Do-itTogether, edited by Sarah Baker, 46-61. Routledge: New York.

Baker, Sarah. 2017. Community Custodians of Popular Music's Past: A DIY Approach to Heritage. Routledge: New York.

Baker, Sarah and Jez Collins. 2015. "Sustaining popular music's material culture in community archives and museums." International Journal of Heritage Studies 21 (10): 983-996.

doi:10.1080/13527258.2015.1041414. 
Baker, Sarah and Jez Collins. 2016. "Popular music heritage, community archives and the challenge of sustainability." International Journal of Cultural Studies.

doi:10.1177/1367877916637150.

Baker, Sarah and Alison Huber. 2013. "Notes towards a typology of the DIY institution: Identifying do-it-yourself places of popular music preservation." European Journal of Cultural Studies 16 (5): 513-530. doi:10.1177/1367549413491721.

Bly, Lyz and Kelly Wooten, eds. 2012. Make Your Own History: Documenting Feminist and Queer Activism in the 21st Century. Litwin Books: Los Angeles.

Boulay, Nadine, Mylène Gamache, Liz Millward and Jen Portillo. 2012. "Desiring Young Les(bi)an Visionaries in the Archive." Australian Feminist Studies 27 (72): 189-203. doi: 10.1080/08164649.2012.676761.

Brager, Jenna and Jami Sailor. 2012. "Archiving the Underground." In Make Your Own History: Documenting Feminist and Queer Activism in the 21st Century, edited by Lyz Bly and Kelly Wooten, 45-55. Litwin Books: Los Angeles.

Caswell, Michelle and Marika Cifor. 2016. "From Human Rights to Feminist Ethics: Radical Empathy in the Archives." Archivaria 81: 23-43.

Chenier, Elise. 2009. "Hidden from Historians: Preserving Lesbian Oral History in Canada." Archivaria 68: 247-269.

Chenier, Elise. 2016. "Reclaiming the Lesbian Archives." Oral History Review 43(1): 170-182. doi:http://10.1093/ohr/ohw025.

Cohen, Sara, Robert Knifton, Marion Leonard and Les Roberts, eds. 2015. Sites of Popular Music Heritage: Memories, Histories, Places. Routledge: New York.

Collins, Jez and Oliver Carter. 2015. "'They're Not Pirates, They're Archivists': The Role of Fans as Curators and Archivists of Popular Music Heritage" In Preserving Popular Music Heritage: Do-it-Yourself, Do-it-Together, edited by Sarah Baker, 126-138. Routledge: New York.

Cooper, Danielle. 2013. "Welcome Home': An Exploratory Ethnography of the Information Context at the Lesbian Herstory Archives." In Feminist and Queer Information Studies Reader, edited by Patrick Keilty and Rebecca Dean, 526-541. Litwin Books: Sacramento.

Cooper, Danielle. 2015. "House proud: an ethnography of the BC Gay and Lesbian Archives." Archival Science: 1-28. doi:10.1007/s10502-015-9250-8.

Cvetkovich, Ann. 2003. An Archive of Feelings. Duke University Press: Durham. 
Darms, Lisa. 2012. "Preserving Contradiction: The Riot Grrrl Collection at the Fales Library." Women \& Performance: a journal of feminist theory 22 (2-3): 335-341. doi:

10.1080/0740770X.2012.720823.

DiVeglia, Angela L. 2012. "Accessibility, Accountability, and Activism." In Make Your Own History: Documenting Feminist and Queer Activism in the 21st Century, edited by Lyz Bly and Kelly Wooten, 69-88. Litwin Books: Los Angeles.

Dunn, Kevin and May Summer Farnsworth 2012. "We ARE the revolution: Riot grrrl press, girl empowerment and DIY self-publishing." Women's Studies 41 (2): 136-157.

Eichhorn, Kate. 2010. "D.I.Y. Collectors, Archiving Scholars, and Activist Librarians: Legitimizing Feminist Knowledge and Cultural Production Since 1990." Women's Studies 39 (6): 622-646. doi:10.1080/00497878.2010.490716.

Eichhorn, Kate. 2013. The Archival Turn in Feminism: Outrage in Order. Philadelphia: Temple University Press.

Eichhorn, Kate. 2014. "Beyond digitisation: a case study of three contemporary feminist collections." Archives and Manuscripts 42 (3): 227-337. doi:10.1080/01576895.2014.958866.

Flinn, Andrew. 2007. "Community histories, community archives: Some opportunities and challenges." Journal of the Society of Archivists 28(2): 151-176.

doi:10.1080/00379810701611936.

Flinn, Andrew. 2011. "Archival activism: independent and community-led archives, radical public history and the heritage professions." InterActions: UCLA Journal of Education and Information Studies 7(2): 1-20.

Flinn, Andrew, Mary Stevens and Elizabeth Shepherd. 2009. "Whose memories, whose archives? Independent community archives, autonomy and the mainstream." Archival Science 9(1): 71-86. doi:10.1007/s10502-009-9105-2.

Freedman, Jenna. 2012. "Self-Publication with Riot Grrrl Ideals: Zines $\neq$ Vanity Press Publications.

” In Make Your Own History: Documenting Feminist and Queer Activism in the 21st Century, edited by Lyz Bly and Kelly Wooten, 13-22. Litwin Books: Los Angeles.

Gilliland, Anne and Sue McKemmish. 2014. "The Role of Participatory Archives in Furthering Human Rights, Reconciliation and Recovery." Atlanti: Review for Modern Archival Theory and practice (24): 78-88. 
Gumbs, Alexis Pauline. 2012. "Eternal Summer of the Black Feminist Mind: A Queer Ecological Approach to the Archive." In Make Your Own History: Documenting Feminist and Queer Activism in the 21st Century, edited by Lyz Bly and Kelly Wooten, 59-68. Litwin Books: Los Angeles.

Halberstam, Judith. 2005. In a Queer Time and Place: Transgender Bodies, Subcultural Lives. New York University Press: New York.

Haraway, Donna. 1988. "Situated Knowledges: The Science Question in Feminism and the Privilege of Partial Perspective." Feminist Studies 14 (3): 575-599. doi:10.2307/3178066.

Huvila, Isto. 2008. "Participatory archives: towards decentralised curation, radical user orientation, and broader contextualisation of records management." Archival Science 8 (1): 1536. doi:http://10.1007/s10502-008-9071-0.

Keilty, Patrick and Rebecca Dean, eds. 2013. Feminist and Queer Information Studies Reader. Litwin Books: Sacramento.

Kumbier, Alana. 2014. Ephemeral Material: Queering the Archive. Litwin Books: Sacramento.

Leonard, Marion. 2007. "Constructing Histories Through Material Culture: Popular Music, Museums and Collecting." Popular Music History 2 (2): 147-167.

McLeod, Dayna, Jasmine Rault and T.L. Cowan. 2014. "Speculative Praxis Towards a Queer Feminist Digital Archive: A Collaborative Research-Creation Project." Ada: A Journal of Gender, New Media, and Technology (5). doi:10.7264/N3PZ573Z.

Manalansan, Martin F IV. 2014. "The 'Stuff' of Archives: Mess, Migration, and Queer Lives." Radical History Review (120): 94-107. doi:10.1215/01636545-2703742.

Madden, Ed. 2013. "Queering Ireland, in the Archives." Irish University Review 43 (1): 184-221. doi:10.3366/iur.2013.0064.

McKinney, Cait. 2015. "Body, Sex, Interface: Reckoning with Images at the Lesbian Herstory Archives." Radical History Review (122): 115-128. doi:10.1215/01636545-2849567.

Mitchell, Caroline. 2015. "Re-Sounding Feminist Radio: A Journey through Women's Community Radio Archives." Feminist Media Histories 1 (4): 126-143.

doi:10.1525/fmh.2015.1.4.126.

Moore, Niamh. 2017. "Weaving archival imaginaries: researching community archives." In The Archive Project: Archival research in the social sciences, edited by Niamh Moore, Andrea Salter, Liz Stanley and Maria Tamboukou, 129-152. Routledge: New York. 
Nestle, Joan. 1990. "The Will to Remember: The Lesbian Herstory Archives of New York." Feminist Review (34): 86-94. doi:10.2307/1395308.

O'Meara, Erin. 2012. "Perfecting the new Wave of Collecting: Documenting Feminist Activism in the Digital Age." In Make Your Own History: Documenting Feminist and Queer Activism in the 21st Century, edited by Lyz Bly and Kelly Wooten, 107-121. Litwin Books: Los Angeles.

Petro, Anthony M. 2015. "The Queer Archive of Catholic Sexual Abuse." Radical History Review (122): 160-176. doi:10.1215/01636545-2849594.

Piepmeier, Alison. 2012. "Archives as Activism: a Preface." In Make Your Own History: Documenting Feminist and Queer Activism in the 21st Century, edited by Lyz Bly and Kelly Wooten, ix-xi. Litwin Books: Los Angeles.

Reitsamer, Rosa. 2015. "Alternative Histories and Counter-Memories: Feminist Music Archives in Europe." In Preserving Popular Music Heritage: Do-it-Yourself, Do-it-Together, edited by Sarah Baker, 91-103. Routledge: New York.

Rose, Gillian. 1997. "Situating Knowledges: Positionality, Reflexivities and Other Tactics." Progress in Human Geography 21 (3): 305-320. doi:10.1191/030913297673302122.

Samer, Roxanne. 2014. "Revising 're-vision': Documenting 1970s feminisms and the queer potentiality of digital feminist archives." Ada: A Journal of Gender, New Media, and Technology (5). doi:10.7264/N3FF3QMC.

Sheffield, Rebecka Taves. 2014. "The Bedside Table Archives: archive intervention and Lesbian intimate domestic culture." Radical History Review (120): 108-120. doi:10.1215/016365452703751.

Sheffield, Rebecka Taves. 2016. "More than Acid-Free Folders: Extending the Concept of Preservation to Include the Stewardship of Unexplored Histories." Library Trends 64 (3): $572-$ 584. doi:10.1353/lib.2016.0001.

Taavetti, Riikka. 2015. "A marshall in love. Remembering and forgetting queer pasts in the Finnish archives." Archival Science: 1-19. doi:10.1007/s10502-015-9251-7.

Thistlethwaite, Polly J. 1998. "Building 'A Home of Our Own': The Construction of the Lesbian Herstory Archives." In Daring to Find Our Names: The Search for Lesbigay Library History, edited by James V. Carmichael Jr., 153-174. Greenwood Press: Westport.

Wakimoto, Diana K, Christine Bruce and Helen Partridge. 2013. "Archivist as Activist: lessons from three queer community archives in California." Archival Science 13 (4): 293-316.

doi:10.1007/s10502-013-9201-1. 
Withers, Deborah. 2014. "Re-enacting process: temporality, historicity and the Women's Liberation Music Archive." International Journal of Heritage Studies 20 (7-8): 688-701. doi:10.1080/13527258.2013.794745.

Withers, Deborah M. 2015a. "Intangible Cultural Heritage and the Women's Liberation Music Archive." In Sites of Popular Music Heritage: Memories, Histories, Places, edited by Sara Cohen, Robert Knifton, Marion Leonard and Les Roberts, 125-139. Routledge: New York.

Withers, Deborah M. 2015b. Feminism, Digital Culture and the Politics of Transmission: Theory, Practice and Cultural Heritage. Rowman \& Littlefield International: London.

Wooten, Kelly. 2012. "Outreach and Instruction at the Sallie Bingham Center." In Make Your Own History: Documenting Feminist and Queer Activism in the 21st Century, edited by Lyz Bly and Kelly Wooten, 39-44. Litwin Books: Los Angeles.

X, Ajamu, Topher Campbell and Mary Stevens. 2009. "Love and Lubrication in the Archives, or rukus!: A Black Queer Archive for the United Kingdom." Archivaria 68: 271-294.

\section{Endnotes}

[1] Withers $(2014,691)$ points to punk as subset of a 'malestream', which may not be inclusive of women.

[2] As Eichhorn (2013) herself pointed out, this is not necessarily always the case -- communitybased archives like the Lesbian Herstory Archives have outlasted many institutional archives, partly due to the fact that their independence rendered them relatively unaffected by the neoliberal restructuring and funding cuts which caused so many other archives to collapse. 